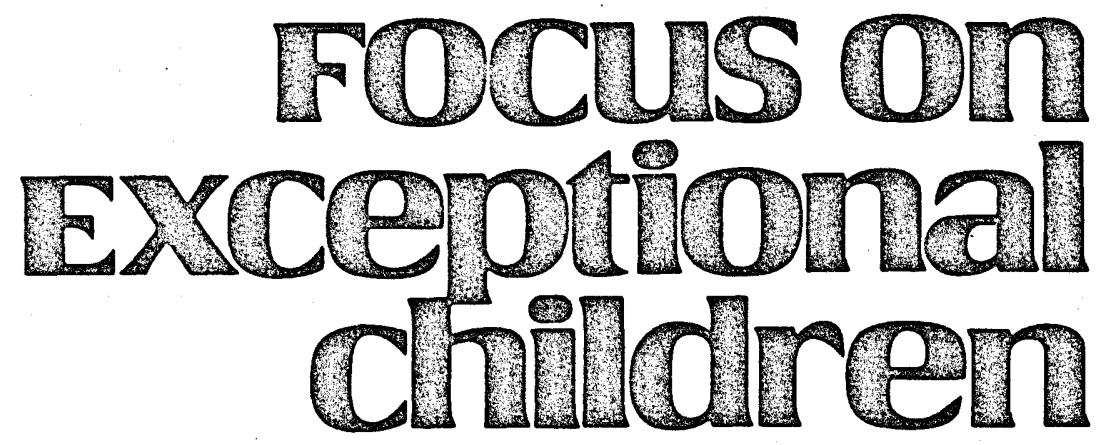

\title{
Social Coordination as a Component of Social Competence in Young Children with Disabilities
}

\author{
Joan Lieber and Paula J. Beckman
}

Substantial evidence shows that young children with disabilities frequently have difficulty with social interaction (Guralnick \& Weinhouse, 1984). Although the interactions of children with disabilities and their peers do not seem to be any more negative than the interactions of nondisabled children and their peers, evidence suggests that the overall frequency of interactions is much lower (Beckman, 1983; Guralnick, 1990; Guralnick \& Weinhouse, 1984). For example, Beckman (1983) found that preschool children with disabilities engaged in fewer and shorter behavior chains than their nondisabled peers. One reason may be that longer interchanges depend on more sophisticated social skills including the ability to coordinate social behavior with that of a partner. From our perspective, social coordination should be distinguished from social interaction. Whereas social interaction includes any exchange that occurs between partners, social coordination requires additional sophistication.

In this article we review what is currently known about social coordination in young children with disabilities. A discussion of the role of social coordination in developing social competence is followed by a description of how social coordination develops in children with and without disabilities. Next we discuss how available assessments of social skills address the concept of social coordination. Finally we identify intervention strategies that may be useful in facilitating social coordination.

\section{THE IMPORTANCE OF COORDINATING SOCIAL BEHAVIOR}

One important component of social competence that is associated with more sophisticated behavioral exchanges between children involves the ability to coordinate behavior with that of a partner. For example, social coordination occurs when a toddler looks at her partner, points to a toy, makes a sound, then looks back at her partner. The toddler and her partner are simultaneously coordinating their attention to each other and to an object. Thus, social coordination requires the ability to coordinate the focus of attention, the timing, and the sequence of behaviors with that of a social partner.

Joan Lieber is an Assistant Professor and Paula Beckman is an Associate Professor at the University of Maryland, College Park.

(c) Love Publishing Company, 1991. 
Further, social coordination involves exchanges in which a child matches his or her behavior to the behavior of a partner. This matching can be based on components such as affect, theme of the exchange, roles played by the participants, or content of the play. For example, in a recently observed interaction between two preschool children, a boy approached a girl, grabbed a doll out of her arms, and said, "I need your baby! It's time for her doctor's appointment." The girl clutched the doll and retorted, "No!" Although social interaction clearly occurred, these children were not successful in achieving social coordination because they did not agree on how the play would proceed.

The ability to coordinate behavior in this way seems to be a complex behavioral process that involves combining many other skills and, for children without disabilities, develops over time (Brownell, 1986). Increasing evidence in the literature concerned with children who do not have disabilities suggests that the ability to coordinate social behavior and play is a critical aspect of social development (Eckerman, Davis, \& Didow, 1989).

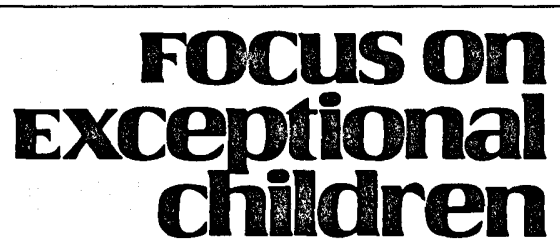

ISSN 0015-511X FOCUS ON EXCEPTIONAL CHILDREN (USPS 203-360) is published monthly except June, July, and August as a service to teachers, special educators, curriculum specialists, administrators, and those concerned with the special education of exceptional children. This publication is annotated and indexed by the ERIC Clearinghouse on Handicapped and Gifted Children for publication in the monthly Current Index to Journals in Education (CIJE) and the quarterly index, Exceptional Children Education Resources (ECER). It is also available in microfilm from Xerox University Microfilms, Ann Arbor, MI. Subscription rates: Individual, \$27 per year; institutions, $\$ 36$ per year. Copyright (c) 1991, Love Publishing Company. All rights reserved. Reproduction in whole or part without written permission is prohibited. Printed in the United States of America. Second class postage is paid at Denver, Colorado. POSTMASTER: Send address changes to:

$$
\begin{aligned}
& \text { Love Publishing Company } \\
& \text { Executive and Editorial Office } \\
& 1777 \text { South Bellaire Street } \\
& \text { Denver, Colorado } 80222 \\
& \text { Telephone (303) 757-2579 }
\end{aligned}
$$

Edward L. Meyen

University of Kansas

Richard J. Whelan

University of Kansas Medical Center
Holly T. Rumpler Senior Editor tanley F. Love

Publisher
Glenn A. Vergason Georgia State University
Even as we have argued that social coordination is at su- $^{-}$ portant skill to be developed for its own sake, evidence also indicates that social coordination plays a role in the development of other domains as well. Vygotsky (in Bruner, 1985) suggests that learning in the areas of cognition and language takes place through social coordination, that a child advances and learns with the help of an adult or a more competent peer. This learning occurs when the environment is arranged so that children are asked to participate in problem solving or communication just slightly beyond what they would be capable of alone. Further, adults or more competent peers allow children to participate in these challenging activities that are beyond their current level of development by scaffolding the activity so children meet with success.

Other theorists and researchers (e.g., Snow, 1984) have similarly described the importance of social coordination in developing cognition and language. Snow posits that very young children learn a variety of communicative functions through social routines with caregivers. These include learning labels for objects through "hide-and-find" games, and learning turn taking through "give-and-take" games. As children get older and become more linguistically competent, interaction with others can lead to improved vocabulary and contribute to syntactic sophistication (Gleitman, Newport, \& Gleitman, 1984). In addition, pragmatic functions, including requesting, asserting, and metalinguistic knowledge, are achieved through social coordination.

Although most of the research that relates development in cognition and language to social coordination deals with the influence of adults, some evidence indicates that social coordination with peers leads to growth in these domains as well. For example, Forman and Cazden (1985) found that peer collaboration on a task led to more sophisticated problem solving than either child was capable of when working alone.

\section{THE DEVELOPMENT OF SOCIAL COORDINATION}

\section{Sequence In Children Without Disabilities}

The ability to coordinate social behavior is reflected in a variety of ways throughout the first few years of life and seems to emerge in a predictable sequence (Howes, Unger, \& Seidner, 1989). By the beginning of the second year, most infants without disabilities become increasingly able to coordinate attention to persons and things (Eckerman et al., 1989). This includes joint attention with another person on a common object and joint manipulation of an object. Most evidence suggests that this ability is not present in the first year of life without an adult's help (Bakeman \& Adamson, 1984).

Social coordination also seems to be an important part of 
complementary play. Howes (1987) describes complementary and reciprocal play as play in which partners take turns and also exchange roles. Thus, at a given point, the play of two partners is different, but complementary. Mueller and Lucas (1975) describe two key features of complementary play: (a) role reversal and (b) reciprocally dependent actions. Thus, in complementary play, both participants have specific roles to play. If one child initiates a social interchange, the partner is constrained in responding and must reciprocate with an act matched to the initiator's act. For example, one child runs to the middle of the room; the other child chases him, then they reverse roles.

Another strategy that can be observed in the more complex interactions of toddlers and preschoolers is the ability to engage in games with peers. Eckerman et al. (1989) define games as lasting for at least two turns of action for each child, agreeable to both children, and having a common topic. A common topic or theme seems to be an especially important feature of children's games. Brenner and Mueller (1982) identified a number of common games that emerged across different toddler play groups. Examples included peek-a-boo and object exchanges. When longer exchanges occurred, they were more likely to be centered on a common topic. Further, a common topic was more likely to be established by older toddlers. Similarly, Eckerman et al. (1989) found that the frequency and duration of games increased over time for dyads, with imitative or imitative and complementary games being largely responsible for the growth.

Somewhat later, the ability to coordinate social play with "pretend" play emerges (Howes, 1985). For example, children may play together in the "house" area of a classroom with one assuming the role of mother and the other the role of father. Howes et al. (1989) and Fein, Moorin, and Enslein (1982) have shown that coordinating pretend play with another child is more difficult and occurs later than solitary pretend play. Social pretend play is considered more complex than other forms of social play because the child must not only be able to behave both nonliterally and socially but also must coordinate these two activities.

Another strategy that characterizes the play of socially competent children is the ability to direct and organize play. During the preschool years, the interaction between peers taps an increasing ability to collaborate in the mutual construction of play. Goncu (1987) describes four phases of social play and the ways children maintain their play activity through the different phases.

1. Entering the play group. Preschool children make indirect attempts to enter, such as standing and watching others play, and more direct attempts, such as asking if they can join the play.

2. Initiating the play itself. Children may accomplish this by simply beginning to play or by discussing the play in advance.

3. Maintaining and extending the play.

4. Terminating the play. For preschoolers, this often occurs by leaving the play area.

Beckman and Lieber (in press) offer more detailed description of this development.

In summary, the complexity and sophistication of social coordination change substantially from the toddler period to the end of the preschool period. The progression is from simple act-react interchanges to play episodes that involve entering into a play group, initiating play, expanding and extending play through negotiation, and terminating play. All of these strategies involve the ability to coordinate play with peers. Table 1 summarizes the developmental changes in social coordination with peers for children who are developing normally.

\section{Social Coordination in Children with Disabilities}

Few studies have directly assessed the ability of children with disabilities to coordinate increasingly complex social behavior. A number of studies, however, have investigated specific skills that, when combined, allow children to coordinate social behavior.

\section{Initiation}

The ability to initiate a social exchange is probably the most widely studied aspect of social competence for young children with disabilities (e.g., Beckman, 1983; Field, 1980). It is included here not because it requires social coordination but, rather, because it is a necessary skill for participating in social exchanges.

Literature in the area of initiations suggests that children with disabilities may have difficulty initiating social exchanges with peers. In an investigation of toddlers in a center-based early intervention program, Lieber, Beckman, and Strong (1991) found that these children initiated about five times during a 15-minute observation. This rate was similar to the initiation rates of younger children without disabilities in other studies (Holmberg, 1980; Mueller \& Brenner, 1977). But Lieber et al. found that when toddlers did initiate, they were relatively successful. They obtained a response more than $75 \%$ of the time.

Herink and Lee (1985) found similar results with older children. They observed preschool children with mild or 


\section{TABLE 1}

Development of Socially Coordinated Behavior In Young Children Who Are Developing Normally

Social Coordination Behavior with Peers

Parallel play with eye contact and/or exchanges of a social behavior

Turn taking in similar activities

Imitation in social pretend play

Social exchanges with reversal of the partner's actions

Social exchange within social pretend play

Joint activity with a common plan and integration of pair's actions

\section{Developmental Age \\ 12-15 mos.}

15-20 mos.

20-24 mos.

24-30 mos.

Social pretend play with the same theme but no coordination of activity within the play

Social play with differentiation of leader and follower

Coordinated social pretend with complementary roles

Evidence of access strategies for entry into a play group

Announcement of roles, prior to pretend play

Negotiation of roles during pretend play

Negotiation of the course of action during pretend play

Termination of pretend play episodes

Source: Adapted from "Toward an Interactional Model of Developmental Changes in Social Pretend Play" by A. Goncu in Current Topics in Early Childhood Education (Vol. 7, pp. 108-125), edited by L. G. Katz, 1987, Norwood, NJ: Ablex; and "Social Pretend Play in Toddlers: Paralells with Social Play and with Solitary Pretend" by C. Howes, O. Unger, and L. B. Seidner, 1989, Child Development, 60, pp. 77-84.

moderate mental retardation who were integrated into Headstart classrooms. The children with disabilities initiated $54 \%$ of the exchanges observed, but they had less frequent social exchanges than their peers without disabilities.

Salisbury, Britzman, and Kang (1989) also investigated initiations. They were interested, however, in what types of initiations were used by preschoolers with mild, moderate, and severe disabilities. Children in their study showed a range of initiation forms including verbal, gestural, physical, and proximity-seeking. Further, there was evidence that children combined strategies in an attempt to elicit responses from peers.

The ability to initiate requires not only social interest but other skills as well. Certain basic skills (e.g., the ability to crawl, reach and touch, vocalize) are all mechanisms available to the developing child that allow social contact. Some children may have trouble initiating contact because of conditions that limit these abilities (Walker, 1982). However, as Salisbury et al. (1989) found, because children can initiate contact in a variety of ways, even children with multiple, severe disabilities may be successful in their initiations with peers if they are persistent.

\section{Responsiveness}

An important factor in early social coordination with peers is the ability to respond to the overtures of others. This skill, which appears early in development, seems to truly require the ability to coordinate behavior with others. For children with disabilities, however, responding appropriately to others develops more slowly and is an area of particular difficulty.

In an investigation of the behavior patterns of pairs of friends, including children with and without disabilities, Strain (1984) found a different pattern for responsiveness, as well as for initiations. When children without disabilities extended social initiations to other nondisabled children, they made complimentary verbal statements, initiated play, shared, and participated in activities that resulted in a reward. When the nondisabled children made initiations to the children with disabilities, on the other hand, the former were more likely to initiate physical assistance, affection, and attempt to resolve conflicts. Of more interest here, however, was the likelihood of the children with disabilities responding. Their probability of responding averaged $37 \%$, whereas the probability of responding was $78 \%$ for friends without disabilities.

Further evidence of the difficulty that some children with disabilities have in responding to initiations is provided by Quay and Jarrett (1986). These researchers examined the social reciprocity of preschool children with a variety of mild disabilities who were paired with peers with and without disabilities. They found that children with disabilities initiated interactions but were unable to match their responses to their partner's initiations. For example, in response to friendly initiations by partners, children with disabilities were less likely than children without disabilities to respond in a friendly way, more likely to respond in a negative way, and more likely to ignore initiations. This finding is particularly significant for the study of social coordination because this ability requires more than a simple response; it also requires the ability to match the qualitative aspects of the partner's initiation.

\section{Coordination of Attention to People and Objects}

As children develop, they become more and more able to coordinate their attention both to peers and to objects. During the first year, infants are unable to achieve this coordination. Vandell, Wilson, and Buchanan (1980) reported that 
over the first year, interactions were more frequent as well as longer in the absence of toys. Jacobson (1981) found similar results for 10-month-old infants. By the second year, however, children without disabilities are able to coordinate their attention to toys and peers. In their study, Mueller and Brenner (1977) found that about $83 \%$ of the social interactions for toddlers included physical objects.

Few studies have specifically investigated the coordination of attention to toys and peers in the play of children with disabilities. Those studies that were located reported somewhat inconsistent results. Lieber, Beckman, and Strong (1991) investigated toddlers with disabilities as they interacted with a familiar playmate without a disability and with other toddlers with disabilities in early intervention classrooms. They found that during two 15-minute sessions, toddlers in both settings showed more frequent socially directed behaviors that included objects than behaviors that did not (e.g., smiles, touches, gestures, laughs). In contrast, Field (1980) reported that 3- and 4-year olds with disabilities ranging from mild to severe interacted with peers more frequently when toys were not included (i.e., more frequent looking, smiling, touching, and vocalizing to peers) than when toys were incorporated into peer-directed behavior.

\section{Imitation}

Imitation is yet another critical social skill that children who are developing normally use widely in social interaction. Eckerman et al. (1989) give several reasons why imitation is such an important strategy.

1. Imitation allows young children to achieve social coordination with partners.

2. Imitation can be used whether the partner is or is not behaving in a way that invites participation.

3. Imitation can be used in response to both conventional and idiosyncratic behaviors.

4. Because imitation does not require verbal skills, it is particularly useful for young children.

A number of studies have investigated the use of imitation during free play for young children with disabilities (e.g., Guralnick \& Groom, 1987a, 1987b; Lieber et al., 1991). Although the settings and amount of observational time differed across studies, all found that imitation was a relatively infrequent behavior. For example, Lieber et al. (1991) found that, on average, toddlers imitated other toddlers fewer than one time per 15-minute observational session. In a similar finding with older children, Guralnick and Groom (1987a) reported that 4-year olds who were mildly delayed imitated their partners an average of two times per 15-minute session. Younger (3-year old) and similarly-aged (4-year old) children without disabilities, however, imitated more frequently, averaging four times and seven times per 15-minute sessions, respectively. Thus, imitation clearly is not a strategy that young children with disabilities use often.

\section{Complementary Play}

A number of investigations have detailed the development of complementary play for young children without disabilities (e.g., Eckerman et al., 1989; Mueller \& Lucas, 1975). No studies were found, however, that directly examined complementary play in children with disabilities.

\section{Integration of Pretend Play and Social Play}

Studies focusing on the integration of pretend and social play among children with disabilities show that, in general, they develop these skills in a way similar to children without disabilities, but at a later age. Specifically, children exhibit individual pretend play before they are able to incorporate pretend play into their interactions with peers. In a study of 17 preschool children (mean chronological age $=$ 48 months) with a range of disabilities, Lieber and Beckman (1991) found that more time was spent in manipulative play when children were in dyads than when they played alone. In contrast, when children were alone, they were able to plan before carrying out pretend play (the highest level in the observation system) significantly more than when they were with a partner.

\section{Direction and Organization of Play}

A number of studies have categorized the ability of young children with disabilities to direct and organize play. This category is distinguished, however, by definitions that vary across studies. For example, Strain (1984) observed preschoolers using two categories that involved organizing play: (a) play organizer (i.e., child specifies an activity, role or rules of play for peers) and (b) conflict resolves (given the occurrence of a dispute between children, the child verbally offers a solution). In studies by Guralnick and Groom (1985, 1987a, 1987b), their category, "leads a companion in activities," required organizing play. Finally, Lieber and Van Dyke (1990) adopted a framework developed by Goncu (1987) to describe organizing and directing others within pretend play. That framework had categories such as negotiating roles for pretend and negotiating how the pretend play proceeded.

The categories in the various studies required different levels of social coordination because some included pretend 
play and others did not. When pretend play was included, the social interaction had a nonliteral nature requiring a greater degree of sophistication.

In general, these investigations found that preschool children with disabilities exhibited sophisticated behaviors, but that they showed these behaviors less frequently than children without disabilities. For example, Strain (1984) found that preschool children with disabilities initiated an average of two play organizers and fewer than one instance of conflict resolution per day toward their friend without disabilities. In contrast, the children without disabilities initiated an average of 13 play organizers and two instances of conflict resolution per day toward their friends without disabilities.

\section{ASSESSMENT STRATEGIES}

From the above review, we clearly have limited information concerning social coordination in young children with disabilities. As a field, we are in the initial stages of identifying what skills are required for social coordination and how those skills develop over time. We are further constrained by our knowledge that social coordination is not an all-or-nothing skill but, rather, one that is affected by partner, activity, and materials available for interaction. Thus, the instruments available for assessing this ability are likewise limited.

\section{Assessment Instruments}

Guralnick and Weinhouse (1983) suggest that an instrument designed to assess child-child social interactions should be able to: identify deficits, estimate the severity of the deficits, and provide a developmental framework to plan goals for intervention. In their review of early childhood assessment instruments that tap social development with peers, Guralnick and Weinhouse indicated that $36.5 \%$ had items related to Parten's social participation categories (i.e., solitary, onlooker, parallel, associative, cooperative, games) and $21 \%$ had items about sharing. Fewer instruments assessed aggression (7.5\%), friendship (11.7\%), and initiation/response $(9.1 \%)$. Based on Guralnick and Weinhouse's review, these instruments exclude many of the skills essential to social coordination.

One reason the instruments reviewed by Guralnick and Weinhouse are limited is that they were designed to assess broad-based developmental progress across a variety of domains. For example, in the Batelle Developmental Inventory (Newborg, Stock, Wnek, Guidubaldi, \& Svinicki, 1984) peer interaction is a subset of the social/emotional domain that also includes items related to adult interaction, expres- sion of feelings, self-concept, coping, and social roles. The peer interaction subset contains 17 items spanning the age range from 12 to 83 months. When many developmental areas are assessed, the number of items that target each domain must be kept small so the assessment can be accomplished within a reasonable time period. For early interventionists who are programming for children, however, information from these assessments may not provide sufficient information to plan intervention strategies in a specific domain.

\section{Direct Observation}

One way of supplementing the global information offered by developmental inventories is to directly observe social interactions of young children with disabilities with their peers. LaGreca and Stark (1986) identified a number of advantages of this method, including its face validity and its ability to be used repeatedly to estimate change over time. They also named a number of shortcomings of direct observation. These include two that are particularly relevant for this review: (a) the problems of capturing the sequential nature of social interactions, and (b) the issue of developmental change.

\section{Sequential Nature of Social Interactions}

One of the aspects of social interaction that complicates observation and categorization is that it involves two or more people. To observe the overtures of target children is not sufficient. To note how their behavior affects their peers is also crucial. Further, responsiveness of the target children themselves is critical. Some of the studies reviewed previously included observational systems that incorporated sequences of behavior (Beckman, 1983; Lieber et al., 1991; Quay \& Jarrett, 1986; Salisbury et al., 1989, Strain, 1984), and others did not (Field, 1980; Guralnick \& Groom, 1985, 1987a, 1987b; Herink \& Lee, 1985).

Although these observational systems are available for use by early interventionists, it is difficult to reliably carry out the detailed observations required in many of these systems without videotaping for later analysis. Further, in spite of the complexities inherent in these systems, they do not precisely reflect the complexity of all that occurs during a social interaction. Guralnick (1986) argues that attention must be paid to:

\footnotetext{
... corequisites, prerequisites and other processes related to peer interactions ... including access strategies, content matches, turn-taking, and related characteristics of those communicative exchanges that have been correlated with successful peer interactions. (p. 127)
} 
We have yet to develop instruments that capture this degree of complexity.

\section{Developmental Change in Social Behavior}

LaGreca and Stark (1986) note that although we would all agree that children's social behavior undergoes developmental change, few studies (and, therefore, few instruments) have emphasized developmental change in peer relationships. Within the last several years, we have begun to accrue information related to developmental changes for young children who are not disabled (e.g., Howes, 1987), but we have particularly limited information about developmental changes in young children with disabilities.

Observational measures that identify discrete behaviors have not focused on the development of social interaction from infancy through the preschool years. For example, the categories Strain (1984) uses (e.g., play organizer) are appropriate for children who are more advanced developmentally, but they would be inappropriate for toddlers or children who are less advanced developmentally.

The lack of developmental focus in these instruments has several origins:

1. Some early interventionists and researchers do not believe that developmental sequences are important for children with disabilities, particularly those who have severe disabilities. In this view, focusing on skills that are critical for functioning is more important than emphasizing skills that represent normal developmental progressions.

2. Until recently, most early intervention programs have not included children younger than age 3 ; thus, the development of instruments targeting the social interactions of toddlers with disabilities has not been an issue.

3. Developmental assessments of social competence for young children with disabilities are often based on measures developed for normally achieving children, and even these measures are in their initial stages. Thus, early interventionists have few developmentally based resources.

One approach that may prove fruitful for evaluating the social coordination of young children with disabilities is based on a teacher rating scale that relies on observing, then rating social coordination. The use of a rating scale for evaluating this ability would have several advantages. Rating scales are easy to complete, require less training than microscopic observational systems, and necessitate less frequent reliability checks (Bailey \& Wolery, 1989).
We have developed a Social Processes Rating Scale for teachers. This scale includes items that assess social coordination in young children with disabilities. A rating scale is especially suitable for evaluating this aspect of social competence for several reasons:

1. Teachers can use it efficiently across a variety of social contexts. For example, teachers can rate children's social processes with peers in early intervention programs as well as with other partners (e.g., mother, sibling) in a home setting.

2. It is designed to evaluate children at a range of developmental levels. It is appropriate for a variety of children from those who are simply looking at peers, to children who can coordinate simple initiation and response sequences, to children who can use a variety of strategies to enter group play.

3. It allows teachers to evaluate sequences of behaviors between target children and their partners. Teachers consider children's ability to initiate interaction as well as their responses.

Sample items and definitions from the Social Processes Rating Scale include the following:

Sustains Social Contact: The child uses a variety of strategies to maintain and/or extend exchanges with partners. These might include imitation, talking, staying in proximity, or positive affective behaviors such as smiling, touching, or hugging. In rating the appropriateness of this item, consider the extent to which the strategies used are generally positive and do not persist if the partner actively resists.

Coordinates Object Play with Social Behavior: The child incorporates objects into social interactions. For example, she may offer an object to her partner, play with an object which is being used by her partner, show objects to her partner, reference objects in communication attempts.

Repairs Interactional Breakdowns: The child repeats or changes behavior based on feedback from a partner. For example, the partner says "huh?" "what?" "tell me again," and the child changes or repeats actions to help the partner. This behavior can be nonverbal-for example, the child offers a toy to the partner, the partner does not respond, so the child moves closer and offers the toy again.

\section{INTERVENTION STRATEGIES}

Taken together, the literature reviewed thus far suggests that intervention in the area of social coordination is of major 
importance for young children with disabilities. Although little research to date has focused specifically on the ability to coordinate social behaviors, related literature suggests that a number of intervention strategies are likely to be useful.

\section{Place children with more competent partners.}

When young children with disabilities have more competent social partners, they seem to exhibit more frequent and more sophisticated social behaviors. For example, in a project considering the social behavior of young children with disabilities with different partners, we discovered that children with disabilities engaged in more social interaction when in dyads with a nondisabled partner than while in a center-based setting with peers who had disabilities (Lieber et al., 1991). More competent partners seem to "scaffold" their exchanges in ways that facilitate the social behavior of their less competent partner rather than to simply model more sophisticated behavior. Thus, early interventionists can facilitate social coordination by putting children in mainstreamed settings to make available more competent partners.

\section{Place children in dyads.}

Some evidence suggests that more interaction is observed in dyads than in larger groups (Guralnick \& Groom, 1987a; Lieber et al., 1991). Although the reason for this difference is not clear, one potential factor may be that children might have difficulty coordinating social behavior with more than one person at a time. Thus, teachers can increase social coordination by placing children in dyads for intervention.

\section{Provide social toys.}

A growing body of evidence suggests that certain types of toys influence the social behavior of children. Some toys encourage children to play by themselves; others encourage more interaction. Beckman and Kohl (1984) found that toys that were more social (e.g., puppets, balls) were associated with more social interaction than toys that were considered "isolate" (e.g., books, puzzles).

In a similar study, Martin, Brady, and Williams (1991) used time sampling techniques to investigate the influence of social and isolate toys on the social behavior of children in integrated and nonintegrated preschool settings. They found that children engaged in the most interaction during integrated play with social toys. Even in nonintegrated settings, the incidence of social play almost doubled when social toys were available, compared to the isolate toy condition. They argue that social toys are "setting events" for social interaction. Similarly, Stoneman, Cantrell, and Hoover-Dempsey (1983) found that toys such as blocks and water play were associated with more social exchanges, whereas library, fine motor, and art materials were associated with more solitary play.

There is also evidence that large motor toys encourage more social exchange than fine motor toys. For example, for less sophisticated children, when large, nonportable play equipment is used, interactions tend to be frequent and positive (DeStefano \& Mueller, 1982). Thus, younger children or those with more severe disabilities should be given larger motor toys to encourage social coordination. For older children, social coordination is more likely to occur with social rather than isolate toys.

\section{Identify classroom activities that encourage social ex-} change.

The type of activity in which children engage influences children's interactions. Kohl and Beckman (1984) compared the interactions of children with and without disabilities in four classroom activities: free play, circle, fine motor, and snack. They found that children with disabilities engaged in the most interactions during circle, followed by snack, free play, and fine motor.

This is consistent with the findings of DeKlyen and Odom (1989), who studied the social behavior of 20 children with disabilities and 8 children without disabilities. More interaction was observed in play activities that were structured. Those authors note, however, that their definition of "highly structured play" is play in which the teacher already has taken care of many of the difficult social tasks (e.g., agreeing on a theme, assuming roles, taking turns, handling interruptions).

Interpreting both of these studies from the perspective of social coordination, interactions appear to increase as teachers' assistance increase. This underscores the difficulty that children with disabilities seem to have with more complicated exchanges. It also highlights the importance of developing intervention strategies that center on the more complex aspects of social coordination.

One activity that requires social coordination is sociodramatic play (Strain, 1975; Tremblay, Strain, Hendrickson, \& Shores, 1981). Strain (1975) read familiar stories to children and encouraged them to engage in role-related activities based on the story. This strategy resulted in more social participation. Other activities, such as dress-up or pretending in the kitchen, seem to be associated with greater social participation. 


\section{Teach specific skills that are frequent mechanisms of social coordination.}

The above strategies are indirect in nature, and they involve arranging the social and physical environment to facilitate social coordination. In addition, teachers can intervene directly with the children themselves to enhance the skills that are mechanisms for achieving social coordination. Eckerman et al. (1989) observed that in the first three years of life, several patterns of behavior help children achieve social coordination with a peer. One set of behaviors includes those that reflect a general positive responsiveness to people (e.g., social smiles, attending to people). Young children also use a number of communicative acts (e.g., pointing to something, intentional vocalizations). In addition, they use some behavior patterns that help them achieve joint attention (e.g., looking where someone else points, manipulating an object that someone else is manipulating).

As noted earlier, Eckerman et al. (1989) found that imitation was the predominant behavioral strategy enabling children to coordinate their social behavior with that of a partner. By directly intervening in a child's imitation skills, teachers may provide children with a specific mechanism by which to achieve social coordination.

Finally, teachers can intervene directly with children who are attempting sociodramatic play. Smilansky (1968) identified a number of strategies that can encourage sociodramatic play in preschool children:

Asking questions to get a theme going (e.g., Is your baby hungry?).

- Making suggestions that help get activities going (e.g., Let's bake as cake).

ㅁ Relating behavior to the real world (e.g., I drank milk for lunch today, too).

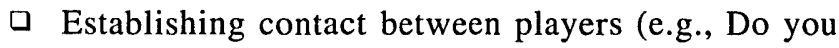
know what is wrong with the baby, Doctor?).

Giving directions that help get an activity going (e.g., Tell the nurse what is wrong with your baby).

Smilansky suggests that if a child is not playing dramatically at all, teachers might initiate a theme, introduce a role, and suggest activities. If the child engages in sociodramatic activity but does so alone, Smilansky suggests helping the child establish contact with other children by encouraging the child to incorporate others into his or her solitary play theme.

\section{CONCLUSION}

Studies specifically focused on social coordination in young children with disabilities are limited. Nevertheless, the literature suggests that social coordination may be a fruitful area of inquiry for investigators. Moreover, social coordination may be a promising avenue for interventionists. Although considerable progress has been made in facilitating basic social skills (such as initiating), we have made less progress with respect to the more complex and subtle aspects of social competence. By facilitating children's ability to coordinate their social behavior, we may provide a vehicle with which they can achieve sophisticated exchanges.

\section{REFERENCES}

Bailey, D. B., Jr., \& Wolery, M. (1989). Assessing infants and preschoolers with handicaps. Columbus, $\mathrm{OH}$ : Charles E. Merrill.

Bakeman, R., \& Adamson, L. B. (1984). Coordinating attention to people and objects in mother-infant and peer-infant interaction. Child Development, 55, 1278-1289.

Beckman, P. J. (1983). The relationship between behavioral characteristics of young children and social interaction in an integrated setting. Journal of the Division for Early Childhood, 10, 69-77.

Beckman, P. J., \& Kohl, F. L. (1984). The effects of social and isolate toys on the interactions of integrated and nonintegrated groups of preschool children. Education \& Training of the Mentally Retarded, 19, 169-174.

Beckman, P. J., \& Lieber, J. (in press). Parent/child social relationships and peer social competence of preschool children with disabilities. In S. L. Odom, S. R. McConnell, \& M. A. McEvoy (Eds.) Social competence of young children with disabilities: Nature, development, and intervention. Baltimore: Paul H. Brookes.

Brenner, J., \& Mueller, E. (1982). Shared meaning in boy toddlers' peer relations. Child Development, 53, 380-391.

Brownell, C. A. (1986). Convergent developments: Cognitive-developmental correlates of growth in infant/toddler peer skills. Child Development, 57, 275-286.

Bruner, J. (1985). Vygotsky: A historical and conceptual perspective. In J. V. Wertsch (Ed.). Culture, communication, and cognition: Vygotskian perspectives (pp. 21-34). Cambridge, MA: Cambridge University Press.

DeKlyen, M., \& Odom, S. L. (1989). Activity structure and social interactions with peers in developmentally integrated play groups. Journal of Early Intervention, 13, 342-352.

DeStefano, C. T., \& Mueller, E. (1982). Environmental determinants of peer social activity in 18-month-old males. Infant Behavior \& Development, 5, 175-183.

Eckerman, C. O., Davis, C. C., \& Didow, S. M. (1989). Toddlers' emerging ways of achieving social coordination with a peer. Child Development, 60, 440-453.

Fein, G. G., Moorin, E. R., \& Enslein, J. (1982). Pretense and peer behavior: An intersectoral analysis. Human Development, 25, 392-406.

Field, T. (1980). Self, teacher, toy, and peer-directed behaviors of handicapped preschool children. In T. Field, S. Golberg, D. Stern, \& A. M. Sostek (Eds.), High-risk infants and children: Adult and peer interactions (pp. 313-326). New York: Academic Press. 
Forman, E. A., \& Cazden, C. B. Exploring Vygotskian perspectives in education: The cognitive value of peer interaction. In J. V. Wertsch (Ed.). Culture, communication, and cognition: Vygotskian perspectives ( $\mathrm{pp}$. 323-347). Cambridge, MA: Cambridge University Press.

Gleitman, L. R., Newport, E. L., \& Gleitman, H. (1984). The current state of the motherese hypothesis. Journal of Child Language, 11, 43-79.

Goncu, A. (1987). Toward an interactional model of developmental changes in social pretend play. In L. G. Katz (Ed.). Current topics in early childhood education (Vol. 7, pp. 108-125). Norwood, NJ: Ablex.

Guralnick, M. J. (1986). The peer relations of young handicapped and nonhandicapped children. In P. S. Strain, M. J. Guralnick, \& H. M. Walker (Eds.) Children's social behavior: Development, assessment, and modification (p. 93-140). New York: Academic Press.

Guralnick, M. J. (1990). Social competence and early intervention. Journal of Early Intervention, 14, 3-14.

Guralnick, M. J., \& Groom, J. M. (1985). Correlates of peer-related social competence of developmentally delayed preschool children. American Journal of Mental Deficiency, 90, 140-150.

Guralnick, M. J., \& Groom, J. M. (1987a). Dyadic peer interactions of mildly delayed and nonhandicapped preschool children. American Journal of Mental Deficiency, 92, 178-193.

Guralnick, M. J., \& Groom, J. M. (1987b). The peer relations of mildly delayed and nonhandicapped preschool children in mainstreamed playgroups. Child Development, 58, 1556-1572.

Guralnick, M. J., \& Weinhouse, E. (1983). Child-child social interactions: An analysis of assessment instruments for young children. Exceptional Children, 50, 268-271.

Guralnick, M. J., \& Weinhouse, E. (1984). Peer-related social interactions of developmentally delayed young children: Development and characteristics. Developmental Psychology, 20, 815-827.

Henrink, N., \& Lee, P. C. (1985). Patterns of social interaction of mainstreamed prechool children: Hopeful news from the field. The Exceptional Child, 32, 191-199.

Holmberg, M. C. (1980). The development of social interchange patterns from 12 to 42 months. Child Development, 51, 448-456.

Howes, C. (1985). Sharing fantasy: Social pretend play in toddlers. Child Development, 56, 1253-1258.

Howes, C. (1987). Social competence with peers in young children: Developmental sequences. Developmental Review, 7, 252-272.

Howes, C., Unger, O., \& Seidner, L. B. (1989). Social pretend play in toddlers: Parallels with social play and with solitary pretend. Child Development, $60,77-84$.

Jacobson, J. L. (1981). The role of inanimate objects in early peer interaction. Child Development, 52, 618-626.

Kohl, F. L., \& Beckman, P. J. (1984). A comparison of handicapped and nonhandicapped preschooler's interactions across classroom activities. Journal of the Division for Early Childhood, 8, 49-56.

LaGreca, A. M. \& Stark, P. (1986). Naturalistic observations of children's social behaviors. In P. S. Strain, M. J. Guralnick, \& H. M. Walker (Eds.). Children's social behavior: Development, assessment, and modification (pp. 181-213). New York: Academic Press.

Lieber, J., \& Beckman, P. J. (1991). The role of toys in individual and dyadic play among young children with handicaps. Journal of Applied Developmental Psychology, 12, 189-203.
Lieber, J., Beckman, P. J., \& Strong, B. N. (1991, April). The social interactions of toddlers with handicaps: The effects of social context. Presentation at Society for Research in Child Development, Seattle.

Lieber, J., \& Van Dyke, S. (1990, October). Social integration in an integrated preschool program: The use of symbolic play. Presentation at International Early Childhood Conference on Children with Special Needs, Albuquerque, NM.

Martin, S. S., Brady, M. P., \& Williams, R. E. (1991). Effects of toys on the social behavior of preschool children in integrated and nonintegrated groups: Investigation of a setting event. Journal of Early Intervention, 15, 153-161.

Mueller, E., \& Brenner, J. (1977). The origins of social skill and interaction among playgroup toddlers. Child Development, 48, 854-861.

Mueller, E., \& Lucas, T. (1975). A developmental analysis of peer interaction among toddlers. In M. Lewis \& L. A. Rosenblum (Eds.), Friendship and peer relations (pp. 223-257). New York: Wiley.

Newborg, J., Stock, J. R., Wnek, L., Guidubaldi, J., \& Svinicki, J. (1984). The Battelle development inventory. Allen, TX: DLM Teaching Resources.

Quay, L. C., \& Jarrett, O. S. (1986). Social reciprocity in handicapped and nonhandicapped children in a dyadic play situation. Journal of Applied Developmental Psychology, 7, 383-390.

Salisbury, C. L., Britzman, D., \& Kang, J. (1989). Using qualitative methods to assess the social-communicative competence of young handicapped children. Journal of Early Intervention, 13, 153-164.

Smilansky, S. (1968). The effects of socio-dramatic play on disadvantaged preschool children. New York: Wiley \& Sons.

Snow, C. E. (1984). Parent-child interaction and the development of communicative ability. In R. L. Schiefelbusch \& J. Pickar (Eds.), The acquisition of communicative competence (pp. 69-108). Baltimore: University Park Press.

Stoneman, Z., Cantrell, M. L., \& Hoover-Dempsey, K. (1983). The association between play materials and social behavior in a mainstreamed preschool: A naturalistic investigation. Journal of Applied Developmental Psychology, 4, 163-174.

Strain, P. S. (1975). Increasing social play among severely mentally retarded preschool children with socio-dramatic activities. Mental Retardation, 13, 7-9.

Strain, P. S. (1984). Social behavior patterns of nonhandicapped and developmentally disabled friend pairs in mainstream preschools. Analysis and Intervention in Developmental Disabilities, 4, 15-28.

Tremblay, A., Strain, P. S., Hendrickson, J. M., \& Shores, R. E. (1981). Social interactions of normally developing preschool children. Behavior Modification, 5, 237-253.

Vandell, D. L., Wilson, K. S., \& Buchanan, N. R. (1980). Peer interaction in the first year of life: An examination of its structure, content, and sensitivity to toys. Child Development, $51,481-488$.

Walker, J. A. (1982). Social interactions of handicapped infants. In D. Bricker (Ed.), Intervention with at-risk and handicapped infants (pp. 217-232). Baltimore: University Park Press. 


\section{NEW}

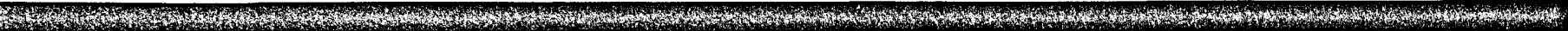

ehind Special Education

Critical analysis of Professional Culture and School Organization

iomas M. Skrtic

niversity of Kansas

is new work is a critical analysis of the nature disability, special education, school ganization, and reform progress. It compares lues to actual outcomes. It asks if what we do what we really believe is best for the children, milies and society. The book develops a nceptual framework to analyze PL 94-142, the gular education initiative, and the excellence ovement. The volume proposes a new ternative configuration for school ganization. All forward thinking educators ll want this new book on their desk. The thor makes a new proposal that allows the cellence goals of general education and the uity goals of special education to be addressed the same time. This innovative text brings w perspectives to the field of special education d regular education for policy and leadership.

9007/paper/ISBN 0-89108-217-4

4.95

\section{Contents}

Part One - PROBLEMS AND PROSPECTS

1. The Crisis in Modern Knowledge

2. Critical Pragmatism as a Method of Social Inquiry

Part Two - PROFESSIONAL CULTURE

3. The Crisis in Special Education

4. The Crisis in the Professions

5. The Special Education Knowledge Tradition

6. Critical Pragmatism as a Mode of Professional Discourse

Part Three - SCHOOL ORGANIZATION

7. Two Discourses on School Organization

8. Toward an Antifoundational Theory of School Organization

9. Special Education and Disability as Organizational Pathologies

10. Special Education Paradox 


\section{Professional update}

January 9-11, 1992

Council for Exceptional Children

Technology and Media Division

Hyatt Hotel

Albuquerque, New Mexico

Contact: Dr. Cindy Okolo

University of Delaware

(302) 451-8695

\section{January 12-14, 1992}

Council for Exceptional Children

Division on Mental Retardation

Hilton Hawaiian Village Hotel

Honolulu, Hawaii

Contact: Dr. Kathleen Marshall

University of South Carolina

(803) 777-6799
March 4-7, 1992

Learning Disabilities Association of America

Atlanta Hilton Hotel

Atlanta, Georgia

Contact: LDA

4156 Library Road

Pittsburgh, PA 15234

\section{April 13-17, 1992}

Council for Exceptional Children

Annual Convention

Baltimore Convention Center

Baltimore, Maryland

Conatct: CEC

1920 Association Drive

Reston, VA 22091

\section{PERMISSIONS AND COPYRIGHT}

All rights are reserved. No part of this publication may be reproduced, photocopied, faxed, stored in a retrieval system, or transmitted, in any form or by any means, electronic, mechanical, recording or otherwise, without the prior written permission of the publisher.
Back issues are available for sale. Reproduction requires permission and payment of fees. It is illegal and a violation of Federal copyright law to reproduce this publication without permission. Direct all inquiries to the permissions editor. 